\title{
From Philosophy to Science: A Brief History of Organic Horticulture in the United States
}

\author{
D.D. Treadwell ${ }^{1}$ and D.E. McKinney ${ }^{1}$ \\ Department of Horticultural Science, North Carolina State University, Box 7609, Raleigh, N.C. 27695 \\ N.G. Creamer ${ }^{2}$ \\ Department of Horticultural Science, and Director Center for Environmental Farming Systems, North Carolina State \\ University, Box 7609, Raleigh, N.C. 27695
}

\begin{abstract}
Since the dawn of agriculture in the Fertile Crescent, people have farmed without synthetic inputs, but does that approach to farming really exemplify the current definition of organic? When did the philosophy and science of organic production develop? Most argue that the industrialization of agriculture in the 1940s served as a point of departure from conventional agriculture, and scientists and farmers, concerned with regenerating soils exhausted by excess tillage, lack of organic amendments, and improper use of chemical fertilizers and pesticides, began to mold a new paradigm. While space limitations prevent a complete review of the rich history, this synopsis follows the evolution of the organic movement and highlights significant events and leaders that would ultimately build U.S. organic agriculture to the dynamic industry it is today.
\end{abstract}

\section{DISCOVERING THE IMPORTANCE OF HUMUS (1500-1700s)}

In the early 1500s, Phillippus Theophrastis Paracelus challenged Aristotle's long held theories on plant nutrition and was the first to recognize that organic constituents, along with water and minerals, were important to plant nutrition. Later, Johann Wallerius concluded in his book Principles of Agricultural Chemistry (1761) that humus was the essential nutritive element of plants. He believed the action of liming the soil dissolved the fatness of the humus, while clay retained the fatness. The phrase living off the fat of the land symbolized the importance of humus to plant nutrition (Waksman, 1938). Wallerius' ideas were formalized later by Albrect Thaer, who is credited with formulating the humus theory of plant nutrition. According to his theory, plant roots extract humus from the soil and when that humus is combined with water, it is transformed into plant substance (Waksman, 1942). The addition of humus to a cropping system was believed to optimize soil physical, biological, and chemical processes, thereby replenishing fertility in a holistic manner not readily achieved by the application of chemical fertilizers, such as Johann Glauber's philosophic dung, a mixture of potassium nitrate and lime (Korcak, 1992).

Although the humus theory had many critics, it also had support from many prominent scientists and the importance of humus would soon become a central concept of the organic movement. Early supporters such as Thaer believed in the natural order and attempted to work within its laws, touting the replenishment of soil with the living, fertile substance of humus. They discouraged an over reliance on chemical fertilizers and warned that their sole use would ultimately lead to soil exhaustion and leave crops vulnerable to pests and disease (Conford, 2001).

\section{DIVERGING PHILOSOPHIES: THE DEVELOPMENT OF THE ORGANIC MOVEMENT AND ESTABLISHMENT OF CHEMICAL FARMING (1700s-1800s)}

Although organic methods have been used since the origins of agriculture some twelve thousand years ago (Mears, 2001), it required a departure from these practices to initiate a movement (Conford, 2001). The Industrial and Scientific Revolution of the 1800s dramatically changed agricultural practices. Some of these changes were positive while others led to an "exploitation of resources and environmental imbalances that were so pervasive they ultimately led to the collapse

${ }^{1}$ Graduate research assistant.

${ }^{2}$ Associate professor, corresponding author. of civilizations" (Howard, 1947). Technological and scientific advances fostered the beliefs within increasingly complex societies that a chemical or machine could be invented to solve any problem (Merrill, 1983). Engineering advances such as the invention of the steam engine facilitated the transport of agricultural goods to distant places. Growers replaced draft horses with steam-powered tractors, enabling them to farm larger areas in less time. Political changes also influenced agricultural philosophies. In England, the 1846 repeal of the Corn Laws resulted in a free trade policy that pioneers of the organic movement deemed disastrous. They argued the growing dependence on imported food not only neglected Britain's obligations to its farming community but also relied heavily upon food imported from other countries with exhausted soils (Conford, 2001).

Advances in chemistry influenced agriculture as well. The humus theory was strongly criticized by Justus von Liebig, who offered a new theory of plant nutrition. He argued that inorganic fertilizers could readily replace manures since it was the minerals, and not other substances in humus or manure, that sustained plant growth. Liebig's $\mathrm{N}-\mathrm{P}-\mathrm{K}$ mentality promoted a reductionist approach, in which the process of food and fiber production was reduced to very basic chemical reactions (Korcak, 1992). The oversimplification of natural systems became a growing concern among some scientists and agriculturalists who felt that production systems were relying too heavily upon technology, rather than biology and ecology. Although the terms ecology and environmentalism were not coined until after 1900 (Barton, 2001), these early regenerative or eco-agriculturalists voiced a collective opinion, promoting not only the benefits of, but also our obligation to preserve, the biological complexity of natural production systems.

\section{EUROPEAN AND ASIAN INFLUENCES ON U.S. AGRICULTURE (1900s-1950s)}

In the U.S., F.H. King, soil scientist and former faculty member at the University of Wisconsin, was becoming increasingly skeptical of domestic agricultural practices and left his position at the United States Department of Agriculture (USDA) Bureau of Soils in Washington, D.C. to study traditional farming practices in the Far East (Tanner and Simonson, 1993). His observations were published in Farmers of Forty Centuries (1911), and provided a detailed account of the importance of maintaining a soil rich in biological diversity to optimize plant productivity. Although King was an American, the majority of U.S. growers were self-admittedly inexperienced in regenerative agricultural techniques compared to their European and Asian counterparts (Conford, 2001). Perhaps the abundance of land resources of a sparsely populated continent deterred the search for restorative agricultural practices. Should a soil's fertility become exhausted, growers simply relocated to new land.

King's work had more of an immediate impact in England than in America. Sir Albert Howard, an English agricultural scientist, was deeply impressed by King and argued a synthesis of western science and traditional agriculture observed by King in Asia could solve problems of agricultural overspecialization (Barton, 2001). Howard believed that soil and human health were intrinsically linked, that manure was essential to soil fertility, and that ample fertility increased crop yields (Howard and Wad, 1931). While director of the Institute of Plant Industry in Indore, India (1924-1931), Howard developed the Indore Process, a composting technique he promoted successfully to the Indian people. Howard is remembered less for his scientific achievements than he is 
for his popular writings on often controversial beliefs, including the belief that plant, animal, and human diseases occurred as a direct result of unhealthy soil (Hershey, 1992). He summarized much of his work and philosophy in An Agricultural Testament (1940), which was read widely despite criticisms from moderate farmers who disagreed with Howard's disdain for technology.

Sharing Howard's opinion of the importance of traditional agriculture was Rudolf Steiner, a well-educated English philosopher who founded the school of anthroposophy in 1913 (Koepf et al., 1976). This school later became known as biodynamic agriculture. Steiner argued against specialization, and for a farm developing "as an organism with its own foundation, self-enclosed as a living unity and totality." In a series of eight lectures, titled Spiritual Foundations for the Renewal of Agriculture and delivered in 1924, he advocated an agricultural system that centered on nurturing the biological and ecological elements (Steiner, reprinted in 1972). Steiner's agricultural theories were based on the influence of astral and zodiacal forces. This caused some supporters to question the validity of organic practices. Nevertheless, Steiner's ideas influenced many members of the eco-agriculture movement. By 1927, the biodynamic movement was well established in America, as represented by Threefold Farm in New York State owned by Elise Stolting and Gladys Barnett (Conford, 2001). Following Steiner's death in 1925, Ehrenfried Pfeiffer continued the study of biodynamic agriculture in the U.S. with a desire to pursue scientific justification for biodynamic methods.

The work of King, Howard, Steiner, and Pfeiffer was central to the work of a growing number of scientists, philosophers, and farmers who were inciting a revival of rural life in England in response to declining farm quality due to the exploitation of natural resources (Shaw and Chase, 1989). A number of farms were established to demonstrate and investigate scientifically the biological processes of regenerative agriculture, focusing on the relationships among soil, plant, and animal health. Lord Northbourne practiced biodynamic agriculture at his farm in Kent, and is credited with coining the term organic in his 1940 classic Look to the Land. In it, he describes an ecologically balanced, living, and holistic practice of farming, referring to the farm as an organic whole (Northbourne, 1940). Friend Sykes, a farmer and animal breeder, purchased a farm in poor condition and transformed it into a showplace of organic methods by applying Howard's Indore Process and eliminating all factory made fertilizer and feed (Conford, 2001). Lady Eve Balfour was also inspired by Howard and turned her own farm into an experiment center to test his ideas (Conford, 2001).

These farms served as scientific laboratories as well as model systems, demonstrating to local communities that implementing regenerative farming practices not only reduced the prevalence of plant and animal disease and improved yields, but most importantly, that these self-sufficient operations were profitable. This was a positive change from the general sentiment of early ecoagriculturalists, who distrusted scientific methods and provided little data supporting their claims of improved soil quality. The belief that scientific evaluation of claims to the regenerative nature of agriculture, rather than observation alone, must become the chief foundation to define and implement public policy was perhaps the most important dictum of supporters of organic production methods (Barton, 2001).

Although these farms had a positive impact on the quality of rural life in England in the early 1900s, it would be some time later before the English agricultural reform movement would influence Americans. In the inter-war years of the 1920s and 1930s, agriculture was the primary industry in England and the United States (Conford, 2001). In stark contrast with the ideas of early ecoagriculturalists, specialization was promoted by industry and government as the saving grace of agriculture. Large scale production of hens, hogs, and eggs, and the rising popularity of canned food concerned many environmentalists who believed that specialization was responsible for the reduction in farm labor, which in turn reduced the pool of experienced farmers and contributed to the exploitation of resources due to improper soil management (Craven, 1926; Conford, 2001; Gee, 1930). It took the Dust Bowl in the midwestern United States before the American public was willing to admit that there was something wrong with the current paradigm (Merrill, 1983). Soils and Men, the 1938 Yearbook of Agriculture (USDA, 1938) provided an outstanding example of the need to shift toward ecologically sound agricultural practices. Aldo Leopold's developing land ethic (Leopold,
1949) also encouraged an ecological attitude toward people and the land. In the foreword, Henry A. Wallace, U.S. Secretary of Agriculture, wrote: "Nature treats the earth kindly. Man treats her harshly. He overplows the cropland, overgrazes the pastureland, and overcuts the timberland. He pours fertility year after year into the cities, which in turn pour what they do not use down the sewers into the rivers and the ocean...The social lesson of soil waste is that no man has the right to destroy soil even if he does own it fee simple. The soil requires a duty of man which we have been slow to recognize."

The alarm had been sounded for not only philosophers and scientists, but also for the general public and the United States Government. By the early 1950s, U.S. agriculture had "the potential to become an ecologically sound system of farming" (Merrill, 1983). Despite this potential, the shift toward an ecological approach to farming was not yet embraced by the mainstream.

\section{SETBACKS AND EMERGING LEADERS (1950s)}

Encouraged by the availability of petrochemicals and the economic strength of the petrochemical industry that sought new markets following World War II (Merrill, 1983), farmers, scientists, and the public found it difficult to resist chemical inputs that affordably and effectively brought marked increases in agricultural production per acre and per labor hour (Kelly, 1992).

As a consequence, there was a considerable decrease in research and publications related to organic farming methods by the mid-1950s (Harwood, 1983). The petrochemical industry provided considerable funding for continued university research in the areas of fertilizers and pesticides, but little to no funding was available for research on the ecological principles of agriculture (Mergentime, 1994). Therefore, research on soil microbiology and biological control of pests was curtailed severely in favor of further exploration of chemical fertilizer theory and application and expansion of pesticide use (Jacobs, 2000). A major blow to organic agriculture during this period was harsh public criticism of the movement by land grant universities. A dean from one such institution even used the term organic cult in his article "Organic Farming - Bunk" published in 1952 (Throckmorton, 1952). This type of criticism stemmed from a fear that "... [An] anti-fertilizer campaign...might damage the status of important agricultural research" (Throckmorton, 1952). With little support from industry or academic institutions, organic proponents used other means to voice their objections to synthetic farming.

One of the most vocal critics of chemically based agriculture was J.I. Rodale. A staunch supporter of Howard, Rodale dedicated his life to furthering the organic movement. Through books such as Pay Dirt (1945), Organic Front (1948), The Organic Method on the Farm (1949), and Organic Merry-Go-Round (1954) J.I. Rodale questioned the new technologies permeating production practices, and served as a tireless spokesperson for the organic movement. As Philip Conford (2001) writes in The Origins of the Organic Movement: "There is no doubt of [JI Rodale's] central importance to the organic cause in the United States, as spokesman for the ideas of Howard and Pfeiffer, forerunner of Carson's case against pesticides, critic of food additives, inspirer of the next generation of organic farmers and gardeners and populizer of the organic cause through his magazines, books, and plays."

Organic Gardening, first published in 1942 under the name Organic Farming and Gardening, was one of the most widely circulated gardening magazines in the world in the early 1990s (Mergentime, 1994). Today, Rodale Press continues to publish technical information on organic gardening methods. The Rodale Institute Farm in Kutztown, Pa., has initiated long term farming system trials that include organic systems and compost use trials to compare the effects of chemical fertilizers compared with compost.

\section{ENVIRONMENTAL PROTECTION (1960s-1970s)}

Organic agriculture slowly regained public attention in the $1960 \mathrm{~s}$ and 1970s. The organic movement was no longer simply a production method, but had become a forum to stop the proliferation of environmental and societal ills believed to be associated with conventional agricultural production. It gained momentum as public concern for the environment, farm workers, and survival of the family farm rose (Sligh, 2002). 
The publication of Rachel Carson's Silent Spring in 1962 marked the beginning of a new era of public concern for the negative impacts of conventional agriculture on the environment and consumers. Her work criticized the indiscriminate use of chemical pesticides and brought public attention to issues that had been overlooked by pesticide manufacturers, regulators, and users. Carson highlighted ill effects on human health from repeated exposure to pesticides, shed new light on the persistence of petrochemicals in the environment and in our food products, and cited examples of damage to the environment, particularly wildlife, brought on by pesticide use (Carson, 1962). She called for moderation in pesticide application, and for the use of ecologically sound pest control strategies that "did not wreak havoc with the entire natural world" (Carson, 1962).

Silent Spring initiated a heated debate on the use of pesticides and Carson and her work were strongly criticized by the pesticide industry and much of the agricultural community. Carson, however, was successful in winning the attention and support of the general public and the policymakers. Her work spurred government investigation into the pesticide industry as well as its own pesticide application and regulatory programs and contributed to the creation of the Environmental Defense Fund and Environmental Protection Agency (Beyl, 1992). A growing environmental consciousness led to what many call a back to the land movement (Sligh, 2002) for people seeking a simpler agrarian lifestyle (Mergentime, 1994). This was brought on in part by Carson's foundation work, and by the energy crisis of the 1970s (Merrill, 1983). Statistics recording growth in the number of organic farms during the 1960s and 1970s are not available (Harwood, 1983), though it is widely accepted that the number increased considerably during these decades.

\section{SOCIAL JUSTICE AND CONVENTIONAL AGRICULTURE (1960s-1970s)}

The 1960s and 1970s saw an upsurge in public concern for social justice within agricultural production as family farmers and farm workers began to question the social impacts of conventional agriculture. Their criticisms of conventional agriculture drew further interest in the organic farming movement.

The chemical revolution allowed for greater corporate influence over farm production and paved the way for ever expanding farm size to capture economies of scale. This translated into lower food prices and profits for the individual farmer and marked the beginning of the consolidation of agriculture (Sligh, 2002). In addition to the effects of increasing corporate interest, other factors such as an increase in labor efficiency due to improved equipment engineering, the introduction of hybrid varieties, and streamlined transport systems have contributed to a reduction in the number of U.S. farmers in the last seventy years from seven million to two million. Small farms have experienced the greatest reduction in numbers due to corporate buyouts and urbanization (Kimbrell, 2002). Farm families facing the loss of their land and livelihood began organizing in the mid-1950s to bring attention to their plight. In 1955, the National Farmers Organization was created to help family farmers earn a fair price for their goods (Organic Gardening, 2002). Other groups including the American Agricultural Movement and National Family Farm Movement also worked for the preservation of the family farm and this farm-friendly focus complemented the interests of the organic agriculture leaders (Sligh, 2002).

Another social justice concern of this era was the status and working conditions of migrant farm laborers. The formation of the United Farm Workers' Union and campaigns led by its founders, Cesar Chavez and Delores Huerta, brought national attention to hazards of pesticide misuse and poor treatment of those producing, harvesting, and processing a large portion of the American food supply. Chavez's work nurtured a relationship between consumers and food producers, which would play a key role in the continued development of the organic movement (Sligh, 2002).

\section{ORGANIC GROWERS UNITE (1970s-1980s)}

Without the support of public institutions or private agribusiness corporations, organic agriculture required cooperation and organization among the small, but ever growing, number of producers who wished to provide an alternative to conventionally produced goods. One of the earliest organizational efforts was Natural Food Associates (NFA) of Atlanta, Texas, founded by Joe Nichols, M.D. Formed in 1953, NFA sought to connect scattered organic growers, assist them in marketing their products, and provide nutritional and agricultural information to the general public. Through their magazine Natural Food and Farming, NFA provided a forum for idea sharing among organic growers and became a resource for consumers seeking organic goods (Mergentime, 1994). Growers also looked to publications such as Acres, U.S.A., started in 1971 by Charlie Walters. In his work, Walters sought to provide information on organic growing at a large-scale production level and publish research that had been abandoned since the beginning of the chemical revolution (Mergentime, 1994).

Literature from this era and continuing through today reflects the expanded scope of expectations for organic agriculture. Writers/ farmers/philosophers such as Wendell Berry (1977), Wes Jackson(1980), David Kline (1990), and Gene Logsdon (1993), remind readers that agriculture is a relationship between humans and land that impacts not only our ability to produce food, but also to preserve our environment, values, society, and culture. These writers point out that conventional agriculture does not offer a means of integrating production with these concepts. Therefore, they promote an alternative as an imperative to secure a future for agriculture.

From 1970 to the 1980 s, the organic movement grew into a united and effective front to challenge conventional agriculture and established itself as an entity in the American food system. In 1971, the Maine Organic Farmers and Gardeners Association (MOFGA) became one of the first statewide organic networks. They sought to connect growers in the state and promote organic products throughout the East Coast. Two years later, California Certified Organic Farmers (CCOF) was established on the West Coast. These associations worked to establish uniform standards for organic food and develop certification programs to create grower-accountability within the industry (Sligh, 2002). Americans benefited from the European leadership in their efforts to promote organic production. In 1972, the International Federation of Organic Agriculture Movements (IFOAM) was founded to "provide a platform for global exchange and cooperation" and "coordinat[e] the network of the organic movement around the world" (www.ifoam.org). Today, this organization is comprised of members from 100 nations and is a leader in developing cooperative scientific discourse on organic agriculture.

\section{THE GOVERNMENT GETS INVOLVED (1980s-1990s)}

Up until the 1980s, the U.S. government did not formally or significantly address organic agriculture. However, as sales of organic products increased through the 1970s, and demands for research and educational programs became more pronounced, USDA released an important publication, the result of a committee formed in 1979 to address organic production: "Report and Recommendations on Organic Farming" (1980). The bold and far-reaching 94-page report challenged the existing scientific paradigm and attempted to define general principles, philosophies, and specific practices of organic farming while characterizing producers, farms, and markets. Specific recommendations regarding research and extension programming were also included (USDA, 1980). As described in the forward by Secretary of Agriculture Bob Bergland, the report was initiated because "we in USDA are receiving increasing numbers of requests for information and advice on organic farming practices. Energy shortages, food safety, and environmental concerns have all contributed to the demand for more comprehensive information on organic farming technology" (USDA, 1980).

An analysis of the impact of the report concluded that, while a few scientists emerged to follow up on the research ideas presented in the report, most scientists and policy makers viewed the report as irrelevant as they still didn't believe that organic agriculture could have any practical significance (Harwood, 1993). Some of the early key scientists working on organic agriculture, including Miguel Altieri, Steve Gliessman, and Willie Lockeretz, continue to make significant contributions today.

The incoming Reagan administration rejected the report in 1981 and abolished the newly established position of Organic Resources Coordinator held by Garth Youngberg (Madden, 1998). Skepticism about organic farming was common and characterized by comments 
such as this one made by former Secretary of Agriculture Earl Butz: "We can go back to organic farming if we must-we know how to do it. However, before we move in that direction, someone must decide which 50 million of our people will starve" (Butz, 1971).

In an attempt to keep alive the push for a less chemically-intensive and more holistic approach to agriculture, organic agriculture supporters broadened their approach and began using the term sustainable agriculture. While the thought that the principles of organic agriculture would be less offensive if included in the broader concept of sustainability, this change actually may have delayed the U.S. government and Land Grant University system in addressing the specific and unique needs of organic farming. Because organic agriculture has its own specific set of succinct consumer-driven requirements and production constraints, this lack of focused attention was detrimental to furthering the science of organic agriculture.

Another important report was “Alternative Agriculture," a Government Accounting Office (GAO) publication that set the stage for the Low Input Sustainable Agriculture (LISA), the precursor to the USDA Sustainable Agriculture Research and Education (SARE) grants program (USGAO, 1990). The GAO report validated concerns about conventional agriculture and gave the sustainable agriculture movement the credibility to institute political change (Madden, 1998).

The establishment of the USDA competitive grants program LISA was a result of growing public demand for alternative production practices. In 1988, with significant support from Senator Patrick Leahy, and his staff, particularly Kathleen Merrigan, \$3.8 million dollars was designated for the USDA national competitive grants program. This program continues now as SARE and remains the primary source of federal funds for much of the U.S. organic agriculture research and education efforts. Unique to the SARE program is farmer and nongovernmental organization (NGO) involvement in the award decision making process. This reflects the influence these groups have had, and leadership they have provided, in shaping national policy and programs in organic agriculture.

\section{THE MARKET AND MARKETING INFRASTRUCTURE GROWS (1980s-1990s)}

By the 1980s, the organic farming industry had matured and begun to pay close attention to product quality in response to a growing interest in fresh and nutritious foods. Several factors fueled growth in the market through the 1980s and 1990s. The Alar scare of 1989 focused attention on pesticide safety and risk, especially in children. Alar, a growth regulator, was widely used by apple growers to maintain crispness, reduce bruising, and increase shelf life. While the Food and Drug Administration (FDA) downplayed the risk and encouraged children to continue eating apples (Lecos, 1989), there was enough skepticism in the public to fuel exponential growth in consumption of organic foods. ANatural Resource Defense Council report, "Intolerable Risk" (Sewell and Whyatt, 1989), that named Alar as the most potent cancer-causing agent in our food supply was supplemented by a media campaign that included a feature on CBS' 60 Minutes. Despite the fact that some scientists challenged the results of the study, the campaign generated public outrage that resulted in a 250 million dollar loss to apple growers (Wiles et al., 1999). More recently, the debate over genetically modified organisms (GMOs) has also contributed to the increase in market demand for organic products. As the U.S. government has not allowed labeling of genetically modified organisms, consumers not wishing to consume GMO products currently purchase organic foods as GMO use is prohibited in organic production (USDA, 2002). The impact of this has been especially evident with sales of organic dairy products, which have grown over 500 percent between 1994-1999 (Dimitri and Greene, 2002). It is widely believed that consumer avoidance of the genetically modified bovine growth hormone (rBGH), not approved for use in Europe, Canada, Japan, New Zealand, and many other industrialized countries in the world (Buttel, 2000; Martin, 2001), is driving the consumer demand for organic dairy products (Puis, 2000). Finally, between 1979 and 1998, 300,000 farmers lost their farms (USDA, 1998) and due to increased public awareness of the farm crisis, supporting family farmers through buying locally produced food through direct marketing channels became incorporated with the buy organic message (Payne, 2000).
Since the late 1980s, sales of organic products have increased more than $20 \%$ per year worldwide (Dimitri and Greene, 2002). The range of products available has also increased and now includes meat products, milk, eggs, pasta, grains, cereals, snack foods, T.V. dinners, processed foods, and more (Greene, 2001). Certified organic cropland in the U.S. more than doubled between 1992 and 1997, and doubled again from 1997 to 2001 (Dimitri and Greene, 2002). Organic products are now sold in nearly 20,000 natural food stores in the U.S. and $73 \%$ of all conventional grocery stores (Dimitri and Greene, 2002). Total domestic sales of organic products in 2000 was $\$ 7.8$ billion, with fresh produce the top-selling organic category (Dimitri and Green, 2002).

As the organic market grew, so did the requirement for uniform certification standards. What started as grassroots efforts across the country (consumer-farmer partnerships) slowly evolved to involve state governments. California Certified Organic Farmers worked to set uniform standards and to define legally organic. Various state Departments of Agriculture began offering certification programs in the late 1980s. In 1997, 40 organizations (12 state and 28 private) performed certification services (Greene, 2001).

The need for standardization became apparent as the market expanded and national and international trade of products increased. Europe was leading the way with production, certification, and marketing. Most European countries began providing direct financial support for conversion to organic practices by the late 1980 s, and many have set specific countrywide organic transition goals. IFOAM initiated an International Accreditation Service (IOA) in 1992 to insure certification standards met internationally agreed-upon criteria (IFOAM, 2002). In 1991, the United Nations Food and Agriculture Organization (FAO) began developing organic standards as well, as part of Codex Alimentarius.

In 1990, the U.S. Organic Foods Production Act (OFPA) was adopted as Title XXI of the 1990 Farm Bill. The purpose of the act was to establish national standards for the production and handling of foods labeled as organic. The OFPA established the formation of the National Organic Program (NOP) and the National Organic Standards Board (NOSB) to advise the USDA in setting standards. There was a significant grassroots effort from other groups, for example, the Organic Trade Association, CCOF, Rural Advancement Foundation International, USA, and others, to ensure that the OFPA was sensitive to input from NGOs and farmers. While some of the NGOs were eager to work with the USDA, others were distrustful about how USDA might manage and implement the program. When the proposed federal rule was first released in December of 1997, the distrust seemed justified. In the first release, the USDA had allowed for the use of GMOs, sewage sludge, and irradiation in organic agriculture. Because the organic movement was consumer driven, inclusion of those practices would have destroyed the U.S. organic market nationally and internationally. After receiving 275,000 negative comments about the rule, the USDA reversed its position on those issues. A more acceptable version of the rule was re-released in March 2000 and came into effect in October 2002. The text of the federal organic rule can be found on the National Organic Program website (USDA, 2002).

\section{THE SCIENCE COMES OF AGE (1990s-2003)}

The practice of organic farming has historically been ahead of the science, but fortunately this is changing. The Organic Farming Research Foundation, founded in 1990, has been an important force in supporting this shift, not only by awarding more than $\$ 1$ million in grants for organic research through their foundation, but also by producing two key reports that have focused attention on the need for organic systems research and research funding. The first was an analysis of the USDA Current Research Information System (CRIS) for pertinence to organic farming. "Searching for the O-Word" found that only 34 of 30,000 projects were explicitly focused on organic systems, which represented less than one-tenth of one percent of USDA's research portfolio (Lipson, 1997). The second report, "State of the States," evaluated organic farming systems research at Land Grant Institutions (Sooby, 2001). This report summarizes, state-by-state, research relevant to organic production. Whereas the report highlights North Carolina State University, Iowa State University, Ohio State University, and University of West Virginia for their systems approach to organic research, it also reports 
that of the 885,863 available research acres in the land grant system, only 151 acres $(0.02 \%)$ were being used for certified organic research. In 2000, OFRF initiated a Scientific Congress on Organic Agriculture Research (SCOAR) to bring together producers and scientists with the intent of building a long-term organic research and education agenda based on a whole systems approach to understanding and improving organic production, marketing, and community development. Already, SCOAR has played a role in informing policy makers about research needs. Federal funding has increased for organic research, and in 2002 and 2003 there were USDA Cooperative State, Research, Education, and Extension Service (CSREES) funds earmarked for organic transition studies. In addition to this targeted funding, other USDA funding has been awarded for organic projects, including large grants awarded in 2001 and 2002 by the USDA-IFAFS program to form the Organic Agriculture Consortium [Ohio State University (lead), North Carolina State University, Iowa State University, Tufts University, and the Organic Farming Research Foundation] and the Northeast Organic Network [Cornell University (lead), New England Small Farm Institute, Northeast Organic Farming Association (New York and New Jersey), Connecticut Agricultural Experiment Station, Organic Crop Improvement Association, New York Certified Organic, University of Maine, Ruckytucks Farm, Rutgers University, and Organic Materials Review Institute].

Whereas grassroots pressure has been important in developing the political will to provide increased funding for organic research, the science is now expanding in its own right. Indeed, the ecological and biological mechanisms that explain some of the often-ridiculed theories long held by organic farmers are being elucidated. For example, organic farmers have long claimed that healthy soils lead to healthier plants that are more resistant to pests and diseases. Now research that describes the importance of soil biology and the role that compost (Zhang et al., 1996) and particulate organic matter (Stone et al., 2001) can play in systemic acquired resistance to plant disease is contributing to the mechanistic explanation of the immune response phenomenon in crops. Confirming long-held beliefs by organic farmers that organic systems are more resistant to pest outbreaks, research conducted at Ohio State University found that european corn borer (Costrina nubilalis) adults laid 18 times as many eggs on corn plants grown on conventionally managed soils as on corn raised on organically managed soils (Phelan et al, 1996). This stimulated further work to determine the biological mechanisms involved. Studies of soil biodiversity in organic farming systems suggest that organic plots will be less dependent on external inputs and more reliant on internal biological cycles (Mader et al, 2002). Other studies suggest that organic systems increase soil quality, reduce negative environmental impacts, and are more energy efficient (Reganold et al, 2001). Comparative studies are becoming more common. For example, root diseases are consistently less severe in organic systems (van Bruggen, 1995). Organic farming practices reduce soil erosion (Reganold et al., 1987), enhance soil physical (Jordahl and Karlen, 1993), biological (Fraser et al, 1988), and chemical (Scow et al., 1994) properties, and enhance nutrient cycling and retention in soils (Arden-Clarke and Hodges, 1988). Finally, reviewing 154 site-years of published studies and reports comparing yields of corn, soybeans, wheat, and tomatoes produced organically to those produced conventionally in the U.S., Liebhardt (2001) found that yields under organic production averaged $95 \%$ of those in conventional systems. As the science has become more challenging and complex, it has become a favorite topic area of research for interdisciplinary groups of scientists. Land grant universities are responding by supporting their efforts and hiring individuals whose job descriptions specifically require and expect work on organic agriculture, including research and extension.

\section{THE FUTURE}

The effect of the NOP on the organic industry is still being debated and evaluated. The impact of this legislation on small farmers is of key concern. The expense and paperwork required for small diversified farms to become certified can be prohibitive, and many small farms are dropping their certification as a result. Those producers that have already developed markets are finding it less necessary to go through the expense and effort of certification, though new organic farmers generally must go through the process as they develop their market. Scale may also impact the availability of inputs, again favoring large farmers. For example, very large organic farms may have no access to organic cover crop seed in the quantities they need, so are allowed to purchase less expensive nonorganic seed, while small organic producers who can find the limited quantities must purchase the more expensive seed. In those cases, profit margins will heavily favor the larger farmers. In addition, sourcing organic transplants or seed sources can be timeprohibitive for small, diversified organic farms as they are sometimes growing more than one hundred varieties per season. This again favors large less diversified operations.

The organic market depends upon consumer acceptance of a rigorous standard. Even with the federal rule in place, the integrity of the standard remains at risk. In February 2003, a rider was placed on the Omnibus spending bill in Congress that weakened the standard by eliminating the requirement that organic feeds be fed to certified organic animals. This rider, designed to serve a particularly vocal constituency in Georgia, contradicted the 10-year process that developed the standard. Fortunately, bipartisan and USDA support for a bill to reinstitute the original standard is making its way through congress as this paper is being written. Maintaining the integrity of organic production will be key to growth and stability in the industry.

Perhaps the biggest concern to long-time supporters of organic agriculture is described as the industrialization of organic agriculture as large multinational corporations enter the marketplace. As suggested by Michael Pollan (2001), organic agriculture has come to imply a set of values that go well beyond a list of inputs that a farmer can or can't use. The question being asked is will these founding values be lost as organic agriculture is industrialized? Will organic agriculture be reduced to input substitution where approved organic inputs are simply substituted for nonallowed substances, or will implementation of a more holistic, ecologically based system of management serve as the foundation for production and marketing decisions? Discussions are emerging on how to incorporate some of the founding values in a beyond organic concept. For example, incorporating local production through attaching food miles (as a way to reward local production) or implementing social stewardship standards or standards of economic equity. These issues are challenging but the discussions are important as we continue to strive for a more sustainable agriculture.

\section{Literature Cited}

Arden-Clarke, C. and R.D. Hodges. 1988. The environmental effects of conventional and organic/biological farming systems. II. Soil ecology, soil fertility, and nutrient cycles. Biol. Agr. Hort. 5(3):223-287.

Barton, G. 2001. Sir Albert Howard and the forestry roots of the organic movement. Agr. History 75(2):168-87.

Berry W., 1977. The unsettling of America. 3rd ed. Sierra Club Books, San Francisco.

Beyl, C.A. 1992. Rachel Carson, silent spring, and the environmental movement. HortTechnology 2:272-275.

Buttel,F.H. 2000. The recombinant BGH controversy in the United States: Toward a new consumption politics of food? Agr. Human Values 17:5-20.

Butz, E. 1971. Crisis of challenge/Nation's agriculture July-August 19. Ctr. Resour. Econ.. Farm Bill Revisited, Wash., D.C.

Carson, R. 1962. Silent spring. Houghton Mifflin, Boston.

Conford, P. 2001. The origins of the organic movement. Bell and Bain, Glasgow.

Craven, A.O. 1926. Soil exhaustion as a factor in the agricultural history of Virgina and Maryland, 1606-1860. Univ. Ill., Urbana.

Dimitri, C., and C. Greene. 2002. Recent growth patterns in the U.S. organic foods market. USDA-ERS Mkt. Trade Econ. Div. Resour. Econ. Div. Bul. 777.

Fraser, D.G., D.G. Doran, W.W. Sahs, and G.W. Lesoing. 1988. Soil microbial populations and activities under conventional and organic management. J. Environ. Qual. 17:585-590.

Gee, W. 1930. The place of agriculture in American life. Macmillan, New York.

Greene, C. R. 2001. U.S. organic farming emerges in the 1990s: Adoption of certified systems. USDA-ERS Mkt. Trade Econ. Div. Resour. Econ. Div. Bul. 770.

Harwood, R.R. 1983. International overview regeneration agriculture. Proceedings of workshops on resource-efficient farming methods for Tanzania. Rodale Press, Emmaus, Pa.

Harwood, R.R. 1993. A look back at USDA's report and recommendations on 
organic farming. Amer. J. Alt. Agr. 8(4):150-153.

Hershey, D.R. 1992. Sir Albert Howard and the Indore Process. HortTechnology. 2(2):267-269.

Howard, A. 1940. An agricultural testament. Oxford Univ. Press, Oxford, U.K.

Howard, A. 1947. The soil and health: A study of organic agriculture. DevinAdair, New York.

Howard, A. and Y.I. Wad. 1931. The waste products of agriculture, their utilization as humus. Oxford Univ. Press, London.

International Federation of Organic Agriculture Movements. 2002. The first 10 years of I.F.O.A.M. accreditation program. http://www.ifoam.org Accessed Feb. 2003.

Jackson W., 1980. New roots for agriculture. The Land Institute, Salina, Kan.

Jacobs, L. 2000. Organics: Yesterday, today, and tomorrow. Agr. Outlook Forum Feb. 2000. http://www.usda.gov.

Jordahl, J.L. and D.L. Karlen. 1993. Comparison of alternative farming systems. III. Soil aggregate stability. Amer. J. Alt. Agr. 8:27-33.

Kelly, W.C. 1992. Rodale press and organic gardening. HortTechnology 2 270-271.

Kimbrell, A. 2002. The fatal harvest reader. Island Press, Wash., D.C.

King, F.H. 1911. Farmers of forty centuries; or permanent agriculture in China, Korea, and Japan. Harcourt Brace Publishing, New York.

Kline D., 1990. Great possessions: An Amish farmer's journal. North Point Press, San Francisco.

Koepf, F.H., B.D. Pettersson, and W. Schaumann. 1976. Biodynamic agriculture: An introduction. Anthroposophic Press, Spring Valley, N.Y.

Korcak, R.F. 1992. Early roots of the organic movement: A plant nutrition perspective. HortTechnology 2(2):263-267.

Lecos, C. 1989. Alar use on apples. FDA News Release. P89-12. 26 Mar.

Leibhardt, W. 2001. Get the facts straight, organic agriculture yields are good. Organic Farming Res. Found. Info. Bul. 10.

Leopold, A. 1949. A Sand County almanac (reissue) Ballentine Books, New York.

Lipson, M. 1997. Searching for the "O-Word"; Analyzing the U.S.D.A. C.R.I.S. for pertinence to organic farming. OFRF, Santa Cruz, Calif.

Logsdon G. 1993. The contrary farmer. Chelsea Green Publ., Post Mills, Vt.

Madden, J.P. 1998. The early years of the L.I.S.A., S.A.R.E., and A.C.E. programs. Reflections by the foundation director. Jan. 2003. Western Reg. SARE. http://wsare.usu.edu/history/.

Mader, P., A. Fliessbach, D. Dubois, L. Gunst, P. Fried, and U. Niggli. 2002. Soil fertility and biodiversity in organic farming. Science. 296:1694-1697.

Martin, G. 2001. American journalists win top eco-award for cow hormone story. San Francisco Chronicle 23 Apr.

Mears, J.A. 2001. Agricultural origins in global perspective. In: M. Adas (ed.). Agricultural and pastoral societies in ancient and classical history. Temple Univ. Press, Philadelphia.

Mergentime, K. 1994. Organic industry roots run deep. Organic Times.

Merrill, M.C. 1983. Eco-agriculture: A review of its history and philosophy. Bio. Agr. Hort. 1:181-210.

Northbourne, W.E. 1940. Look to the land. Dent, London.

Organic Gardening. 2002. Our sixty greatest garden secrets. September/ October.

Payne, T. 2000. U.S. farmers markets 2000: A study of emerging trends. USDA March 2003. http://www.ams.usda.gov/directmarketing/FarmMark.pdf .

Phelan, P.L., J.F. Mason, and B.R. Stinner. 1996. Soil-fertility management and host preference by European corn borer, Ostrinia nubilalis (Hubner), on Zea mays L.: A comparison of organic and conventional chemical farming. Agr. Ecosystems Environ. 56(1):1-8.

Pollan, M. 2001. Behind the organic-industrial complex. N.Y. Times Mag. 13 May.

Puis, E.M. 2000. Not in my body: BGH and the rise of organic milk. Agr. Human Values 17(3):285-295.

Reganold, J.P., L.F. Elliott, and Y.L. Unger. 1987. Long-term effects of organic and conventional farming on soil erosion. Nature 330:370-372.

Reganold, J.P., J.D. Glover, P.K. Andrews, and H.R. Hinman. 2001. Sustainability of three apple production systems. Nature 410:926-930.

Rodale, J.I. 1945. Pay dirt. Devin-Adair Co., New York.

Rodale, J.I. 1948. Organic front. Rodale Press, Emmaus, Pa.

Rodale, J.I. 1954. Organic merry-go-round. Rodale Press, Emmaus, Pa.

Sewell, B.H. and R.M.Whyatt. 1989. Intolerable risk: Pesticides in our children's food. Natural Resour. Defense Council.

Scow, K.M., S. Somasco, N. Gunapala, S. Lau, R. Venette, H. Ferris, R. Miller, and C. Shennan. 1994. Transition from conventional to low-input agriculture changes soil fertility and biology. Calif. Agr. 48:20-26.

Shaw, C. and M. Chase. 1989. The imagined past: History and nostalgia. Manchester Univ. Press, U.K.

Sligh, M. 2002. Organics at the crossroads. In: A. Kimbrell (ed.). The fatal harvest reader. Island Press, Wash., D.C.

Sooby, J. 2001. State of the states: Organic system research at land grant institutions 2001-2002. OFRF, Santa Cruz, Calif.

Steiner, R. reprinted in 1972. Agriculture, a course of eight lectures. Wilding and Son, Ltd., Shrewsbury, U.K.

Stone, A.G., A.G. Traina, and H.A.J. Hoitink. 2001.Particulate organic matter composition and pythium damping-off of cucumber. Soil Sci. Soc. Amer. J. 65(3):761-770.

Tanner, C.B. and R.W. Simonson. 1993. Franklin Hiram King: Pioneer scientist. Soil Sci. Soc. Amer. J. 57:286-292.

Throckmorton, R.I. 1952. Organic farming-Bunk! The Reader's Dig. 61: 45-48.

U.S.D.A. 1938. Soils and men; The yearbook of agriculture, 1938. U.S. Govt. Printing Office, Wash., D.C.

U.S.D.A. 1980. Report and recommendations on organic farming. U.S. Govt. Printing Office, Wash., D.C. 1980-0-310-944/96.

U.S.D.A. 1998. A time to act. A report of the U.S.D.A. National Commission on Small Farms. Misc. Publ. 1545 (MP-1545).

U.S.D.A. 2002. National Organic Standards. Jan. 2003. http://www.ams.usda.gov/ nop/NOP/standards.html.

U.S. Gen. Accounting Office 1990. Alternative agriculture: Federal incentives and farmers' options. Rpt. GAO/PEMD-90-12, February.

van Bruggen, A.H.C. 1995. Plant disease severity in high-input compared to reduced-input and organic farming systems. Plant Dis. 79:976-984.

Waksman, S.A. 1938. Humus: Origin, chemical composition and importance in nature. 2nd ed. Williams and Wilkins Co., Baltimore, Md.

Waksman, S. A. 1942. Liebig-The humus theory and the role of humus in plant nutrition, p. 56-63. In: F.R. Moulton (ed.). Liebig and after Liebig. Amer. Assn. Adv. Sci. Special Publ. 16, Wash., D.C.

Wiles, R., K.A. Cook, T. Hettenbach, and C. Campbell. 1999. How 'bout them apples? Pesticides in children's food ten years after Alar. Environ. Working Group, Wash., D.C.

Zhang, W., W.A. Dick, and H.A.J. Hoitink. 1996. Compost-induced systemic acquired resistance in cucumber to pythium root rot and anthracnose. 86(10):1066-1070. 